\title{
11 Health and Wellbeing in the Context of Workplace Spirituality
}

\section{Introduction}

Workplace spirituality has continued to advance during the 12 years of the International Association of Management Spirituality and Religion conference series started in Austria at WU Vienna in 2010. The broad concept of workplace spirituality stretches further back into the twentieth century. The Handbook of Workplace Spirituality and Organizational Performance, Second Edition (Giacalone \& Jurkiewicz, 2010) placed the emphasis in the domain on performance. Taking a difference approach, this chapter places the emphasis, rather, on the constructs of health and wellbeing within the context of workplace spirituality.

The chapter has five sections. The first section explores the context of workplace spirituality and the current state of affairs relevant to the constructs of health and wellbeing, concluding with an emphasis on spiritual vitality. The second section examines advances and foci during the decade of the 2010s. The third section looks ahead to the challenges of the 2020s. The fourth section examines the methods of inquiry into health and wellbeing within the context of workplace spirituality. Finally, the fifth major section identifies key publications relevant to health, wellbeing, and spiritual vitality.

The chapter distinguishes spirituality from religion, the latter being an organized system of beliefs, rituals, and practices established by a church, synagogue, mosque, or other specific organizational religious form (Quick et al., 2008). Hartshorne (1963) makes an important distinction between religion and Biblical faith, the latter falling within the domain of spirituality. The concerns of spirituality are peace, harmony, and transcendence, which means an acceptance of a life centered on others. General conclusions and universal guidelines about spirituality may be difficult to form given its subjective nature (Krishnakumar \& Neck, 2002).

\section{Workplace Spirituality: Context and State of the Art}

We examine three questions as a way of understanding the context of workplace spirituality and the state of the art as a backdrop for the current chapter. These questions are: What is workplace spirituality? What is the basis for justified knowledge and beliefs? How are we to understand health and wellbeing? 


\section{What is Workplace Spirituality?}

Mitroff and Denton (1999) set forth five models of spirituality for the workplace, specifically for corporate organizations. These models are: Religious-based organization; Evolutionary organization, one step removed from a religious-based organization; Revolutionary organization, a more extreme form often led by recovering addicts; Value-based organization, one that has an underlying, implicit dimension of spirituality; and Socially responsible organization, one that appears the most secular. An examination of these five models suggest that there is an underlying continuum of spirituality running from religious to secular organization along which these five models may be arrayed. This approach decouples religion and spirituality, which Quick et al. (2008) explicitly do in discussing spiritual vitality.

Krishnakumar and Neck (2002) explore exactly what is meant by "spirituality" in the workplace. Their thesis is that spirituality is a highly personal, as well as charged, construct that can have positive effects in organizations if allowed to flourish in both its variety and diversity. The authors consider religious views, existential views, and the intrinsic-origin view (i.e., it originates from inside the individual) of spirituality. There is not a uniform agreement nor widely accepted definition of spirituality. Setting aside the organizational performance issue as has been done above, the authors see potential benefits of spirituality in the workplace, including: intuition and creativity, honesty and trust, personal fulfillment, and commitment.

Leadership is a key construct in the study of organizational behaviour (Nelson \& Quick, 2019). Related to workplace spirituality, Fry (2003) sets forth a theory of spiritual leadership that has bearing on health and wellbeing in this context. Fry's model of spiritual leadership incorporates vision, hope/faith, and altruistic love for the purpose of creating vision and value congruence across the leadership spectrum of organizational levels: strategic, team, and individual. Eden (In Press) argues that the science of leadership at its best rests on field experiments that provide actionable cause-and-effect results. While there is much validity in Eden's line of argument, there is a counterpoint to it within the domain of workplace spirituality.

\section{What is the Basis for Justified Knowledge and Beliefs?}

Justified knowledge and beliefs that rest on experimental design as the basis for knowing cause-and-effect relationships is valid within the natural sciences, or the Germanic Naturwissenschaften. The alternative domain is the Geisteswissenschaften, or the spiritual sciences. Within English these may be thought of as the humanities. The spiritual sciences are subjective, interpretative, and rely on history and experience as the basis for justified knowledge and beliefs. Martin Luther argued that he was justified by faith, and faith alone (Metaxas, 2017). While Bowlby (1988) argued that authority had no place in science, this is only true for the natural 
sciences. As Eden (in press) rightly points out, knowledge and beliefs in this domain are justified by experimentation, debate, and empirical evidence.

The same rules of evidence do not necessary apply in the spiritual domain. There is a place in spiritual for authority, depending on the person's individual spiritual beliefs. The ancient scriptures of the Holy Bible, the Koran, the Buddhist texts, and Hindu Vedas are among those authoritative sources. The spiritual person may not have a God or deity as a primary authority figure, though many do. These sources of authority stand in contrast to the authority of the organization and workplace, the latter being manifest in the leaders of the organization. One of the challenges of spirituality in the workplace is that of addressing this issue of dual authority. Lynch (2017, p. $\mathrm{x}$ ) illustrates this in his discussion of "The Faith of the Centurion" (Matthew 8: 5-13). The centurion has a paralyzed servant who is suffering terribly. The centurion has also heard that Jesus Christ has the power to heal and so he defers to this authority in seeking help for his servant, without violating his own chain of command within the Roman Legion. The faith of the centurion is reported to account for the healing.

\section{How Can We Understand Health and Wellbeing?}

Such faith healings are often met with skepticism and doubts or questions are always legitimate in the pursuit of knowledge and the truth. Health and wellbeing are not exact sciences but their protection and enhancement should not be left to chance or faith alone. Within the context of workplace spirituality, health and wellbeing can be understood along four dimensions (Quick et al., 2008). These are: physical health, psychological wellbeing, spiritual vitality, and ethical character. Leadership has a joint responsibility with the individual members of the workplace to enhance these four dimensions of health and wellbeing. Much of physical health and even psychological wellbeing may fall under the authority of modern medical science, which can work in concert with the spiritual sciences. For example, a young physician attending the Choctaw in an Oklahoma Indian Hospital was mistaken for a chaplain when a patient mistook his black diagnostic book for a Holy Bible. The patient asked the physician to pray for him. Choosing not to clarify or debate, the young physician simply sat down with the man, then prayed for his healing and recovery. The physician later marveled at the man's healing, recovery, and release, all of which came more quickly than the medical prognosis had indicated.

\section{Advances and Foci during the 2010s}

What have been the advances and foci in health and wellbeing during the 2010s? The emphasis here is on psychological wellbeing, spiritual vitality, and ethical character, 
which are three key dimensions of health and wellbeing. The five advances discussed are: positivity (Fredrickson, 2013), gratitude and forgiveness (Cameron, 2007), inner peace and spiritual fitness (Lynch, 2017), coaching with compassion (Boyatzis \& Jack, 2018), and developing leaders with character and emotional competence (Wasylyshyn \& Gupta, 2021).

\section{Positivity}

Fredrickson (2013) revised her 3-to-1 positivity ratio and wisely concluded that positivity is not an exact science. However, positive thoughts and emotions impact physiology and behavior. A key aspect of her approach is the balance between the positive and the negative. Individuals who experience a roughly 1-to-1 ratio of positive to negative thoughts and emotions are difficult to spend time with due to the heavy dose of negativity; these people drain energy from others. The positive extreme are individuals who experience ratios of something like 11-to-1 positive to negative thoughts and emotions. These hyper-positive people are very difficult to engage and have a real challenge engaging life's real difficulties and challenges. Those individuals who have a ratio between these extremes have enough negativity to anchor them to reality yet sufficient positivity to give them lift and optimism. Positivity can be contagious in a good way just as infectious diseases can be contagious in a bad way.

\section{Gratitude and Forgiveness}

The expression of gratitude is a source of energy and renewal for a person that draws attention to the positive without denying the negative (Quick et al., 2013). In the workplace, the negative often takes the form of harm, injury, or damage, be that intentional or unintentional. For this reason, Cameron (2007) recommends forgiveness as a process through which the harm, injury, or damage can be repaired and healing can result. Forgiveness does not deny the harm nor absolve a person of responsibility in causing harm, injury, or damage. Forgiveness does not include forgetting, but rather encourages remembering so that learning may occur and repeat incidents do not occur. Forgiveness rituals are among the spiritual disciplines and practices that lead to healing and recovery from trauma and tragedy.

\section{Inner Peace and Spiritual Fitness}

Spiritual vitality can lead to inner peace and spiritual fitness. Lynch (2017) began his search for inner peace because of the chaos factor in the world around him. A 
modern day centurion as a US Army combat officer, he was physically healthy, psychologically well, and of sound ethical character but in spiritual need. As he searched for inner peace, he discovered a personal pathway anchored in Biblical faith. The pathway was not without twists, turns, and potholes, but it proved a reliable path. Spiritual vitality rests on spiritual fitness, the personal daily habits, rituals, and disciplines that turn life's chaos into an inner peace and order. Lynch's (2017) daily habits for spiritual fitness included prayer, to include confession, lifestyle evangelism, and strong marital bond with his wife. Inner peace and spiritual fitness did not interfere with Lynch's career commitments as he ascended to one of the top 50 commissioned officers in the U.S. Army as a lieutenant general before retiring.

\section{Coaching with Compassion}

Boyatzis and Jack (2018) draw on recent advances in neuroscience that reveals the underlying mechanisms of coaching, leading to coaching with compassion (i.e., coaching to the positive emotional attractor - PEA). They show how neuroscience explains different forms of empathy, drawing on brain regions that are essential to social-emotional connections with others, understanding ethical issues, and being open to new ideas and learning. Their work is very resonant with a value-based organization (Mitroff \& Denton, 1999). Coaching with compassion is as deeply personal as Krishnakumar and Neck (2002) argue spirituality is deeply personal. The person coached with compassion benefits from the experience and so too does the coach or leader who is coaching with compassion. Further, as Boyatzis and Jack (2018) point out, coaching with compassion is more mutually beneficial than coaching for compliance (i.e., coaching to the negative emotional attractor - NEA). Bringing neuroscientific advances into the workplace offers real potential to enhance health and wellbeing.

\section{Character and Emotional Competence}

The character and emotional competence of an organization's leadership can have significant, positive impact of health and wellbeing in the workplace. The leadership of the USAF's largest logistics depot with 13,000 personnel implemented a six year (1995-2001) intervention that prevented all fatalities and saved \$33 million in grievances and conflicts (Quick et al., 2013, p. 118). In another case the commanding general of the US Army's Fort Hood implemented a soldier-focused, family-oriented set of policies that, after one year, resulted in significant improvements in health and wellbeing indicators throughout the installation (Lynch \& Dagostino, 2013, pp. 15-16). These included significant drops in incidences of domestic violence, divorce, and failed relationships. Hence, morale and wellbeing improved with enhanced work-life balance. 
More consequentially, the suicide rate dropped precipitously, taking Fort Hood from the top of the Army list with most suicides to the bottom of the list with the lowest suicide rate. Traffic accidents on this massive installation nearly disappeared. Before, going from a traffic fatality every 15 or 20 days to, at one point, 245 days without a fatality.

Wasylyshyn and Gupta (2021) set out Leadership 3000 model for long-term leadership development that is highly consistent with the value-based organization (Mitroff \& Denton, 1999) and focused on developing leaders of character and emotional competence. In Phase 1 of their four phase model, intensive assessments come from an in-depth life history, an extensive battery of psychometric testing, and targeted organizational interviews. From a health and wellbeing perspective, the key leader behaviors sought include emotional fortitude, courageous leadership, and pragmatic optimism. The leader's ability to use self-awareness, selfmanagement, and relationship-building skills are crucial as is emotional resilience. Emotional competent leaders of good character serve both preventive and therapeutic functions in workplace health and wellbeing.

\section{Challenges for the 2020s}

There are four challenges to extending physical health, psychological wellbeing, spiritual vitality, and ethical character in workplaces around the world. These four challenges are: to validate the subjective, to study the variance or array of human spiritual experience, overcome totalitarianism and tyranny of the majority in the workplace, and manage effectively a dual authority system.

\section{Validate the Subjective}

Krishnakumar and Neck (2002) advance the case that workplace spirituality is highly personalized, which also means that it is not highly generalizable. Spiritual vitality cannot be imposed upon the person but rather can be invited from within the person. This rests on the authors intrinsic-origin view of spirituality. For workplace spirituality to flourish thus requires that the organization validate or affirm, without necessarily agreeing with or endorsing, the subjective human experience of spirituality. The standardization of processes and of objects within a workplace can have significant economic value. The attempt to standardize human beings in the workplace works against their basic nature, especially in the spiritual and ethical realms. 


\section{Study the Variance or Array of Spirituality}

William James (1902) delivered a classic series of twenty Gifford Lectures at Edinburgh, Scotland from 1901 to 1902 that explored the varieties of religious experience, starting with attention to religion and neurology. Now over a century later and in the context of workplace spirituality would be a time to use James' earlier exploration as a touchstone for studying the variance and array of spiritual experience in the workplace. While the Handbook of Workplace Spirituality and Organizational Performance, Second Edition aims somewhat in that direction, it comes from an organizational and performance point of view. What is required here is a study with primary concern for health and wellbeing in the workplace, and particular attention to spiritual vitality and ethical character. While physical health and psychological wellbeing may be well addressed, spiritual vitality and ethical character are not always so (cf. Quick et al., 2008).

\section{Overcome Totalitarianism and Tyranny of the Majority}

Schwartz (1990) focuses attention on how totalitarianism and narcissistic process, as manifest in the organizational ideal, are toxic and lead to corporate decay. These are just the antithesis of spiritual vitality and ethical character in the workplace. There are limits to the legitimate authority and power of leadership in any organization and when that becomes overbearing and uncaring, it stifles workplace spirituality. However, followers have a responsibility in this dynamic as well (see Chapter 12 "Leadership and Followership" in Nelson \& Quick, 2019). Effective followers are neither passive nor dependent. Rather, they are active, engaged, and accepting of responsibility. Like spirituality, good leadership is invitational. Totalitarianism and tyranny have no place in healthy corporate organizations and to the extent that they exist, spiritual vitality and ethical character are suppressed (Schwartz, 1990).

\section{Accept and Manage the Dual Authorities}

As Martin Luther rediscovered, the authority of scripture transcends and is separate from human authority (Metaxas, 2017). This principle of scriptural authority is applicable to a wide range of spiritual beliefs. Hence, in a spiritual vital organization, individuals with spiritual vitality will have dual authorities to consider, and manage. By the same token, organizational leadership has a challenge in acknowledging this dual authority arrangement, if they want to maintain the spiritual vitality of the workplace. The risk here is the classic person-role conflict to which Robert Kahn and his colleagues (1964) referred in their seminal organizational stress studies in role conflict and ambiguity. The spiritual person has an autonomy and integrity of character 
aligned with her/his spiritual beliefs, disciplines, and practices. A central question for the person and the organization is whether these dual authorities can co-exist and be managed for mutual benefit. Acknowledging that in some cases they cannot means that the person-organization relationship should be dissolved.

\section{Methods of Inquiry in Health and Wellbeing}

In contrast to the natural sciences that are reductionist in nature, the sciences of the spirit are holistic in nature; inclusive, not exclusive. The works cited in the advances and foci of the 2010s earlier in the chapter do not have a common method for considering health and wellbeing in the context of workplace spirituality. The methods varied from neurological measures, to psychometric assessments, to biographical inquiry, and finally organizational archival data. The methods and standards for top level psychological research vary depending upon whether the research is quantitative or qualitative, or mixed method (American Psychological Association, 2020: Chapter 3). Health and wellbeing in occupational settings and workplaces is interdisciplinary in nature, drawing on epidemiology, psychology, engineering, as well as spirituality and religion (Macik-Frey et al., 2007; Quick et al., 2013). Therefore, diversity of methods of inquiry adds value and texture to the domain of health and wellbeing.

To really get at the health and wellbeing of American workers, Pfeffer and his colleagues engaged a multi-year epidemiological study to examine morbidity and mortality as well as health care costs (Goh et al., 2016). At the organizational level, the two best indicators of health and wellbeing have been absenteeism and voluntary turnover (Cascio \& Boudreau, 2011). While spirituality may be highly personal and spiritual vitality may be an abstract concept, theory and practice suggest that metaphysical constructs do have consequences in the real world (cf. Kant, 1956).

\section{Key Publications for Health and Wellbeing}

In addition to the various contemporary articles cited earlier in the chapter, there are two key publications to consider for health and wellbeing in the context of workplace spirituality. These are the Handbook of Religion and Health, Second Edition (Koenig et al., 2012) and The SAGE Handbook of Organizational Wellbeing (Wall et al., 2021). The spiritual connections between the mind (psyche) and body (soma) have been explored for decades (cf. Siegel, 1985). Koenig, King, and Carson (2012) provide a comprehensive collection of 29 chapters centered on physical health and mental health (psychological wellbeing). This is a rigorous treatment with connections to religion and spiritual practices. While Siegel (1985) showed what may appear to some miracles, those of faith accept the healing power of gratitude, forgiveness, and love. However, Koenig, King, and 
Carson (2012) also confront the dark side of religious practices that stand in conflict with modern medicine and psychology, leading to harm and even premature death. This work is for the discerning reader and scholar to explore the connections across these important domains of knowledge.

The Wall, Cooper, and Brough (2021) comprehensive handbook of organizational wellbeing is also for the discerning reader and scholar. Organized into four major sections with 40 chapters on a host of dimensions of health, wellbeing, and spirituality in organizations, this puts a direct focus on the organization, the workplace, and occupational settings as the context. However, the chapters on grief, suicide prevention, and spiritual wellbeing are not just constrained to the workplace.

\section{Concluding Comment}

Workplace health and wellbeing may be conceived along four dimensions, which are physical health, psychological wellbeing, spiritual vitality, and ethical character. Health and wellbeing in the context of workplace spirituality is best studied through the spiritual sciences as well as the natural sciences. The latter is nomothetic by nature while the former is idiographic in nature. The idiographic framework is particularly suitable given the highly personalized nature of spirituality in the workplace.

\section{References}

American Psychological Association. (2020). Publication Manual of the American Psychological Association (7th ed.). American Psychological Assocoation. https://books.google.at/books? id $=48$ MkEAAAQBAJ

Bowlby, J. (1988). A Secure Base: Clinical Applications of Attachment Theory. Routledge.

Boyatzis, R. E., \& Jack, A. I. (2018). The neuroscience of coaching. Consulting Psychology Journal: Practice and Research, 70(1), 11-27. https://doi.org/10.1037/cpb0000095

Cameron, K. (2007). Forgiveness in organizations. In D. Nelson \& C. L. Cooper (Eds.), Positive Organizational Behavior. Sage. https://books.google.at/books?id=4AF5nnJMPQQC

Cascio, W. F., \& Boudreau, J. W. (2011). Investing in People: Financial Impact of Human Resource Initiatives (2nd ed.). Pearson Education/FT Press. https://books.google.at/books?id= 1ZIhBAAAQBAJ

Eden, D. (In Press). The science of leadership: A journey from survey research to field experimentation. The Leadership Quarterly. https://doi.org/10.1016/j.leaqua.2020.101472

Fredrickson, B. L. (2013). Updated thinking on positivity ratios. American Psychologist, 68(9), 814-822. https://doi.org/10.1037/a0033584

Fry, L. W. (2003). Toward a theory of spiritual leadership. The Leadership Quarterly, 14(6), 693-727. https://doi.org/10.1016/j.leaqua.2003.09.001 
Giacalone, R. A., \& Jurkiewicz, C. L. (Eds.). (2010). Handbook of Workplace Spirituality and Organizational Performance (2nd ed.). Taylor \& Francis.

Goh, J., Pfeffer, J., \& Zenios, S. A. (2016). The relationship between workplace stressors and mortality and health costs in the United States. Management Science, 62(2), 608-628. https://doi.org/10.1287/mnsc.2014.2115

Hartshorne, M. H. (1963). The Faith to Doubt: A Protestant Response to Criticisms of Religion. Prentice-Hall.

James, W. (1902). The Varieties of Religious Experience: A Study in Human Nature. The Modern Library.

Kahn, R. L., Wolfe, D. M., Quinn, R. P., Snoek, J. D., \& Rosenthal, R. A. (1964). Organizational Stress: Studies in Role Conflict and Ambiguity. John Wiley \& Sons.

Kant, I. (1956). Groundwork of the Metaphysics of Morals. Harper Torchbooks/The Academy Library. [Translated and analyzed by H.G. Paton].

Koenig, H. G., King, D., \& Carson, V. B. (Eds.). (2012). Handbook of Religion and Health (2nd ed.). Oxford University Press. https://books.google.at/books?id=NiRZcCVbkZ4C

Krishnakumar, S., \& Neck, C. P. (2002). The "what", "why" and "how" of spirituality in the workplace. Journal of Managerial Psychology, 17(3), 153-164. https://doi.org/10.1108/ 02683940210423060

Lynch, R. (2017). Work Hard, Pray Hard: The Power of Faith in Action. Simon \& Schuster.

Lynch, R., \& Dagostino, M. (2013). Adapt or Die: Leadership Principles from an American General. BakerBooks. http://public.ebookcentral.proquest.com/choice/publicfullrecord.aspx?p= 3117406

Macik-Frey, M., Quick, J. C., \& Nelson, D. L. (2007). Advances in occupational health: From a stressful beginning to a positive future. Journal of Management, 33(6), 809-840. https://doi. org/10.1177/0149206307307634

Metaxas, E. (2017). Martin Luther: The Man Who Rediscovered God and Changed the World. Viking.

Mitroff, I. I., \& Denton, E. A. (1999). A Spiritual Audit of Corporate America: A Hard Look at Spirituality, Religion, and Values in the Workplace (1st ed.). Jossey-Bass Publishers (Warren Bennis signature series).

Nelson, D. L., \& Quick, J. C. (2019). ORGB6: Organizational Behavior. Cengage/South-Western.

Quick, J. C., Cooper, C. L., Gavin, J. H., \& Quick, J. D. (2008). Managing Executive Health: Personal and Corporate Strategies for Sustained Success. Cambride University Press.

Quick, J. C., Wright, T. A., Adkins, J. A., Nelson, D. L., \& Quick, J. D. (2013). Preventive Stress Management in Organizations (2nd ed.). American Psychological Association. https://doi.org/ 10.1037/13942-000

Schwartz, H. S. (1990). Narcissistic Process and Corporate Decay: The Theory of the Organization Ideal. NYU Press.

Siegel, B. S. (1985). Love, Medicine \& Miracles. Harper \& Row Publishers.

Wall, T., Cooper, C. L., \& Brough, P. (Eds.). (2021). The SAGE Handbook of Organizational Wellbeing (1st ed). SAGE Publications Ltd.

Wasylyshyn, K. M., \& Gupta, R. K. (2021). Leadership development: A psychologically-informed process that spawned a generation of CEO's. Management and Business Review, 1(1), 71-78. 